\title{
Demethoxycurcumin-Metal Complexes: Fragmentation and Comparison with Curcumin-Metal Complexes, as Studied by ESI-MS/MS
}

\author{
Wojciech Ostrowski, Lidia Śniecikowska, Marcin Hoffmann, and Rafał Frański \\ Adam Mickiewicz University, Faculty of Chemistry, Umultowska 89B, 61-614 Poznań, Poland \\ Correspondence should be addressed to Wojciech Ostrowski; wostrow@amu.edu.pl
}

Received 23 May 2013; Revised 31 July 2013; Accepted 31 July 2013

Academic Editor: D. Sajan

Copyright (c) 2013 Wojciech Ostrowski et al. This is an open access article distributed under the Creative Commons Attribution License, which permits unrestricted use, distribution, and reproduction in any medium, provided the original work is properly cited.

\begin{abstract}
Two questions are asked: the first is if the lack/presence of methoxyl moiety at aromatic ring essentially affects the stability of curcuminoid-metal complexes, and the second is if it is possible that in the metal complexes one of the possible demethoxycurcumin structures predominates. To answer the first question, the ESI-MS/MS spectra were taken of ions containing demethoxycurcumin, curcumin, and metal cation (e.g., ion [dCurc + Curc- $\mathrm{H}+\mathrm{Pb}]^{+}$), and in order to answer the second question the ESI-MS/MS spectra were recorded of ions containing demethoxycurcumin and metal cation (e.g., ion [dCurc- $\mathrm{H}+\mathrm{Zn}]^{+}$). An interpretation of the mass spectra has indicated that (i) for some metals, curcumin-metal complexes are more stable than demethoxycurcumin-metal complexes and for some metals vice versa, and (ii) in demethoxycurcumin-metal complexes structure B1 [(1E,4Z,6E)-5-hydroxy7-(4-hydroxy-3-methoxyphenyl)-1-(4-hydroxyphenyl)hepta-1,4,6-trien-3-one] is more stable than structure B2 [(1E,4Z,6E)-5hydroxy-1-(4-hydroxy-3-methoxyphenyl)-7-(4-hydroxyphenyl)hepta-1,4,6-trien-3-one].
\end{abstract}

\section{Introduction}

Curcuminoids are natural compounds existing in turmeric, a popular Indian spice. The main curcuminoid is curcumin (Curc, 75-80\%), which reveals interesting biological and pharmacological properties as reviewed recently [1-5]. Two other curcuminoids are demethoxycurcumin (dCur, 15-20\%) and bisdemethoxycurcumin (bdCurc, 3-5\%). These two curcuminoids, and especially dCurc, have also been studied in terms of their biological and pharmacological properties [6-12]; sometimes dCurc exhibited better properties than Curc [13-15]. Curcuminoids have a $\beta$-diketone unit; thus they are able to form stable complexes with metal cations, number of Curc-metal complexes have been reported [16$25]$ and formation of such complexes may have interesting pharmacological implications [26-35]. On the other hand, dCurc-metal complexes have not been studied yet. The only paper on the subject reports that Curc is a better $\mathrm{Cu}$ reducer than dCurc and Curc is more effective than dCurc in DNA cleavage reaction (the reaction is a consequence of $\mathrm{Cu}$ complexation by Curc) [10].

It is well known that even small structural changes in organic compounds may have great impact on their biological activity (as observed for curcuminoids). However, the question is if lack/presence of methoxyl moiety at aromatic ring essentially affects the stability of curcuminoid-metal complexes, since it can be taken for granted that metal cations are chelated by $\beta$-diketone unit, deprotonated enol form of curcuminoids. The demethoxycurcumin molecule, in contrast to other two curcuminoids, is not symmetrical; therefore two oxygen atoms at the aliphatic chain $\left(\mathrm{C}_{3}=\mathrm{O}\right.$ and $\mathrm{C}_{5}=\mathrm{O}$ ) are not chemically identical (Scheme 1 ). But when complex ions are taken, a tautomerism is lost as a result of deprotonation. By analogy to tautomerism, there are two possible structures $\mathrm{B} 1$ and $\mathrm{B} 2$ that can be included in the demethoxycurcumin-metal complexes. Thus, the question is if it is possible that in the metal complexes one of the structures (B1 or B2 shown in Scheme 1) predominates. 
<smiles>COc1cc(/C=C/C(=O)CC(=O)/C=C/c2ccc(O)cc2)ccc1O</smiles><smiles>C/C=C\C(=O)/C=C/c1ccc(O)c(OC)c1</smiles>

Scheme 1: Tautomerism of demethoxycurcumin.

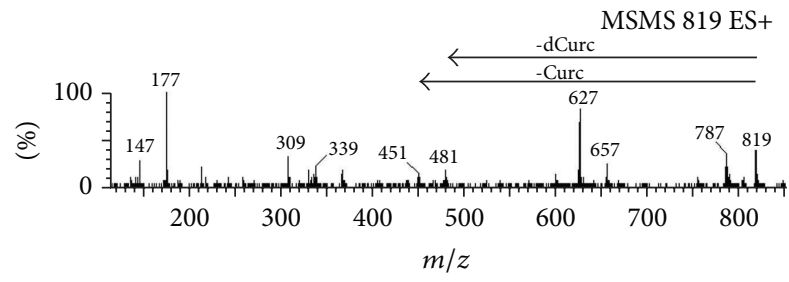

(a)

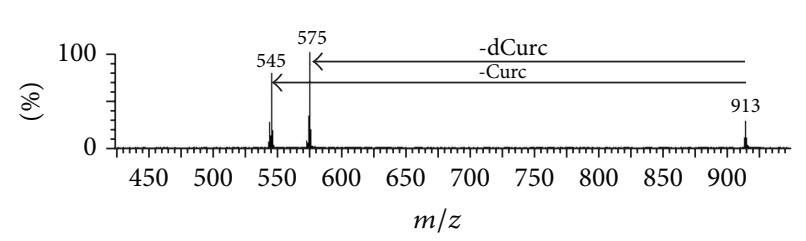

(b)

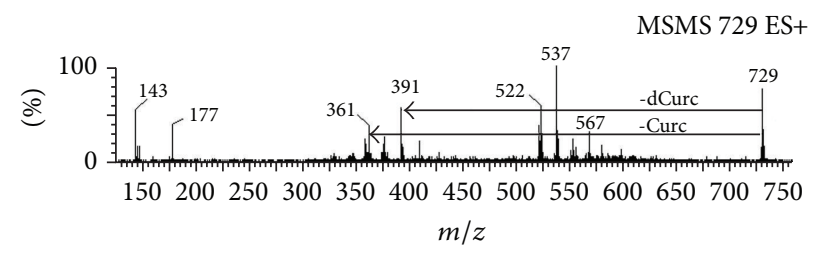

(c)

Figure 1: CID-MS/MS spectra of ions $[\mathrm{dCurc}+\mathrm{Curc}-\mathrm{H}+\mathrm{Cd}]^{+}((\mathrm{a}) \mathrm{CE}=30 \mathrm{~V}),[\mathrm{dCurc}+\mathrm{Curc}-\mathrm{H}+\mathrm{Pb}]^{+}((\mathrm{b}) \mathrm{CE}=15 \mathrm{~V})$ and $[\mathrm{dCurc}+$ Curc- $\mathrm{H}+\mathrm{Mg}]^{+}((\mathrm{c}) \mathrm{CE}=35 \mathrm{~V})$.

The aim of this study is to answer the two formulated questions. The respective ions generated by electrospray ionization (ESI) were subjected to CID (collision-induced dissociation) MS/MS experiments. CID-MS/MS spectra for the complexes of 15 metals were obtained. Obviously, there is little sense to present and discuss all of the results; however, as this work did not focus on complexes of only one metal, it has been decided to show CID-MS/MS spectra of several metal complexes as representative examples.

\section{Materials and Methods}

All reagents were obtained from Sigma-Aldrich (Poznań, Poland). A typical commercial grade curcumin contains about $17 \%$ of demethoxycurcumin [12]. Each methanol solution of curcumin had a concentration $10^{-5} \mathrm{~mol} / \mathrm{dm}^{3}$, and therein metal salt (chlorides) was three times more. Mass spectra were taken on a Waters/Micromass (Manchester, UK) Q-tof Premier mass spectrometer (software MassLynx V4.1, Manchester, UK). The sample solutions were infused into
ESI source by a syringe pump at a flow rate of $5 \mu \mathrm{L} / \mathrm{min}$. The electrospray voltage was set to $2.7 \mathrm{kV}$ and the cone voltage to $-30 \mathrm{~V}$. The source temperature was $80^{\circ} \mathrm{C}$, and the desolvation temperature was $250^{\circ} \mathrm{C}$. Nitrogen was used as the cone gas and desolvating gas at the flow rates of 50 and $800 \mathrm{lh}^{-1}$, respectively. Argon was used as a collision gas at the flow-rate of $0.5 \mathrm{~mL} / \mathrm{min}$ in the collision cell. Collision energy (CE), the most important parameter for MS/MS experiments, was $5-50 \mathrm{eV}$ as indicated in the mass spectra presented. For CID-MS/MS ion mass with the most abundant monoisotopic mass was chosen for each metal (e.g., in the case of [dCurc- $\mathrm{H}+\mathrm{Zn}]^{+}$ion $m / z 431$ was chosen-it contains ${ }^{64} \mathrm{Zn}$ ). Quantum mechanical calculations including full geometry optimization for $[\mathrm{dCurc}+\mathrm{H}]^{+}$and [dCurc$\mathrm{H}+\mathrm{Zn}]^{+}$molecular cations were performed at popular B3LYP density functional level of theory [36] and SDD basis set including Stuttgart-Dresden pesudopotential for the metal center [37]. Wiberg bond indices [38] were calculated with NBO program [39] as implemented in Gaussian 09 [40]. 
MSMS $760 \mathrm{ES}+$

MSMS 773 ES+

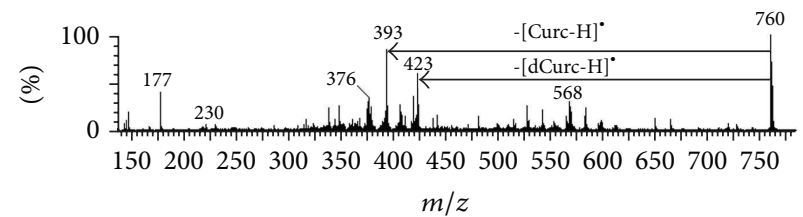

(a)

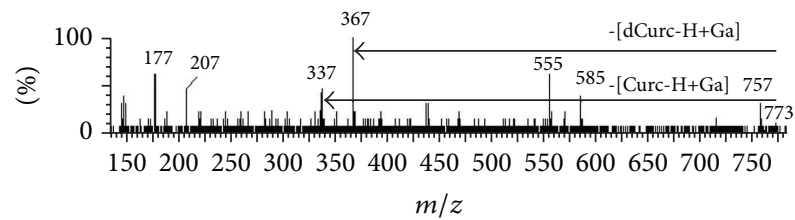

(b)

Figure 2: CID-MS/MS spectra of ions $[\mathrm{dCurc}+\mathrm{Curc}-2 \mathrm{H}+\mathrm{Fe}]^{+}((\mathrm{a}) \mathrm{CE}=35 \mathrm{~V})$ and $[\mathrm{dCurc}+\mathrm{Curc}-2 \mathrm{H}+\mathrm{Ga}]^{+}((\mathrm{b}) \mathrm{CE}=50 \mathrm{~V})$.<smiles>COc1cc(/C=C/C(=O)/C=C([O-])/C=C/c2ccc(O)c(OC)c2)ccc1O</smiles><smiles>CCCCC</smiles><smiles>COc1cc(/C=C/C(=O)C=C=O)ccc1O</smiles><smiles>O=C(/C=C([O-])/C=C/c1ccc(O)cc1)/C=C/c1ccc(O)cc1</smiles><smiles>C1CC1</smiles>
$m / z 217$<smiles>O=C=C=C([O-])C=Cc1ccc(O)cc1</smiles>

SCHEME 2: Fragmentation pathway of curcuminoids (negative mode).<smiles>COc1cc(/C=C/C(=O)/C=C(O)/C=C(O)/C=C(O)/C=C(O)/C=C/c2ccc(O)c(OC)c2)ccc1O</smiles><smiles>CC</smiles><smiles>COc1cc(/C=C/C=O)ccc1O</smiles><smiles>OC(=C\c1ccc(O)cc1)/C=C(O)/C=C/c1ccc(O)cc1</smiles><smiles>C1CC1</smiles>
$\mathrm{m} / z 177$<smiles>O=CC=Cc1ccc(O)cc1</smiles>

SCHEME 3: Fragmentation pathway of curcuminoids (positive mode). 


\section{Results and Discussion}

In order to compare the stabilities of dCurc-metal complexes with Curc-metal complexes, a similar approach was applied to the one used in Cooks' kinetic method [41, 42]. This approach can be also used to study complexes consisting of divalent metal cations and deprotonated organic molecules, provided that there is no significant transition state barrier upon the fragmentation process $[43,44]$. CID-MS/MS spectra were obtained for ions [dCurc + Curc-H + Met] $]^{+}$, where Met stands for a divalent metal cation. These ions can be regarded as containing one neutral organic molecule, one deprotonated organic molecule, and metal cation. It is clear that the deprotonated molecule is more strongly bonded to a metal cation than the neutral molecule. Obviously, dCurc and Curc are so similar that some of the ions [dCurc + Curc$\mathrm{H}+\mathrm{Met}]^{+}$contain deprotonated dCurc and neutral Curc and some of the ions vice versa. Also, in some cases of [dCurc + Curc- $\mathrm{H}+\mathrm{Met}^{+}$ion it is not possible to say definitely which of the molecules is deprotonated (one molecule may be "more deprotonated"). Anyway, the loss of a neutral organic molecule from ions $[\mathrm{dCurc}+\mathrm{Curc}-\mathrm{H}+\mathrm{Met}]^{+}$indicates which of the molecules is bonded more strongly to metal cation. Figure 1 shows CID-MS/MS spectra of ions: [dCurc + Curc- $\mathrm{H}+\mathrm{Cd}]^{+}$, [dCurc + Curc- $\left.\mathrm{H}+\mathrm{Pb}\right]^{+}$, and [dCurc + Curc- $\mathrm{H}+\mathrm{Mg}]^{+}$. It is worth noting that curcumin may protect against lead and cadmium toxicity $[6,28,29,33]$.

The loss of dCurc and Curc from ion [dCurc + Curc- $\mathrm{H}+$ $\mathrm{Cd}]^{+}$occurs with the same efficiency. The loss of dCurc from ions $[\mathrm{dCurc}+\text { Curc- } \mathrm{H}+\mathrm{Pb}]^{+}$and $[\mathrm{dCurc}+\mathrm{Curc}-\mathrm{H}+\mathrm{Mg}]^{+}$ is more efficient than that of Curc. In other words, dCurc and Curc are equally prone to bind with $\mathrm{Cd}^{2+}$; however, Curc is more prone to bind $\mathrm{Pb}^{2+}$ and $\mathrm{Mg}^{2+}$ than dCurc.

Complexes with a trivalent metal cation were also observed, namely, the ions containing two deprotonated organic molecules, that is, [dCurc + Curc- $2 \mathrm{H}+\mathrm{Met}]^{+}$(in this case Met stands for a trivalent metal cation). Obviously, from such ions the loss of a neutral organic molecule cannot be expected. Figure 2 shows the CID-MS/MS spectra of ions $[\mathrm{dCurc}+\mathrm{Curc}-2 \mathrm{H}+\mathrm{Fe}]^{+}$and $[\mathrm{dCurc}+\mathrm{Curc}-2 \mathrm{H}+\mathrm{Ga}]^{+}$. It is worth noting that $\mathrm{Fe}$-curcumin complexes may have interesting pharmacological applications [27, 34, 35].

Ion $[\mathrm{dCurc}+\mathrm{Curc}-2 \mathrm{H}+\mathrm{Fe}]^{+}$loses organic radicals [dCurc- $\mathrm{H}]^{\circ}$ and $[\mathrm{Curc}-\mathrm{H}]^{\circ}$, producing fragment ions [Curc$\mathrm{H}+\mathrm{Fe}]^{+}$and $[\mathrm{dCurc}-\mathrm{H}+\mathrm{Fe}]^{+}$, respectively (formally, it is iron reduction $\mathrm{Fe}^{3+} \rightarrow \mathrm{Fe}^{2+}$ ). As clearly indicated in Figure 2(a), the loss of radical [Curc-H $]^{\circ}$ occurs with higher efficiency than that of radical [dCurc-H] $]^{\circ}$. In other words, dCurc is more prone to bind iron cation than Curc.

Ion $[\mathrm{dCurc}+\mathrm{Curc}-2 \mathrm{H}+\mathrm{Ga}]^{+}$behaves in a different way upon CID conditions. Decompositions of this ion lead to the formation of fragment ions $[\mathrm{Curc}-\mathrm{H}]^{+}$and [dCurc$\mathrm{H}]^{+}$; thus the loss of neutral species [dCurc- $\mathrm{H}+\mathrm{Ga}$ ] and [Curc- $\mathrm{H}+\mathrm{Ga}$ ] takes place, respectively (Figure 2(b), formally gallium reduction $\mathrm{Ga}^{3+} \rightarrow \mathrm{Ga}^{1+}$ takes place). Positive ions of the type $[\mathrm{M}-\mathrm{H}]^{+}$are rather rare in mass spectrometry (M stands for a neutral organic molecule), but sometimes they are observed [45]. The loss of [dCurc-H + Ga] occurs with higher efficiency than the loss of $[\mathrm{Curc}-\mathrm{H}+\mathrm{Ga}]$ which

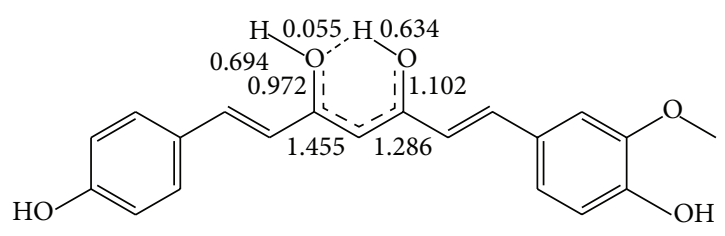

FIgure 3: Bond orders of $[\mathrm{dCurc}+\mathrm{H}]^{+}$ion.

means that dCurc is more prone to bind gallium cation than Curc.

Mass spectrometry has been successfully used for tautomeric study [46-48], and hence it has been tried to use mass spectrometry for dCurc different structures elucidation by analogy to the tautomerism. Mass spectrometric decomposition of deprotonated demethoxycurcumin (negative ion [dCurc- $\mathrm{H}]^{-}$) led to the formation of fragment ions at $\mathrm{m} / \mathrm{z}$ 217 , and 187 , whereas deprotonated curcumin yielded only ion at $m / z 217$ and deprotonated bisdemethoxycurcumin yielded only ion $187[49,50]$. Plausible structures of these fragment ions are shown in Scheme 2. For parent ion [dCurc- $\mathrm{H}]^{-}$, the fragment ion at $m / z 217$ was about twice more abundant than the fragment ion at $m / z$ 187. However, on the basis of this mass spectrometric fragmentation pathway, it is difficult to elucidate which of the dCurc structures (B1 or B2, Scheme 1) predominates.

Mass spectrometric decomposition of protonated demethoxycurcumin (positive ion $[\mathrm{dCurc}+\mathrm{H}]^{+}$) led to the formation of fragment ions at $m / z 177$, and 147 , whereas protonated curcumin yielded only the ion at $m / z 177$ and protonated bisdemethoxycurcumin yielded only ion 147 [51]. Plausible structures of these fragment ions are shown in Scheme 3. $[\mathrm{dCurc}-\mathrm{H}+\mathrm{Met}]^{+}$decomposes in a similar way to $[\mathrm{dCurc}+\mathrm{H}]^{+}$.

For parent ion $[\mathrm{dCurc}+\mathrm{H}]^{+}$, it is reasonable to assume the ion at $m / z 177$ to arise from structure B2 and the ion at $m / z 147$ from structure B1. Because the fragment ion at $\mathrm{m} / z 177$ was about twice more abundant than that at $\mathrm{m} / z 147$ [51], structure B2 seems to predominate over structure B1. The calculated Wiberg indices (bond orders) further support this suggestion, as their values calculated for CC bonds are 1.286 and 1.445. It confirms the abundance of ions at $m / z 147$ and 177-the CC bond from the demethoxy-side is stronger which promotes generation of ion at $m / z 177$ (Figure 3).

The complexes dCurc-metal cation detected in the ESIMS conditions contain deprotonated dCurc, but they are positive ions. Figure 4 shows the MS/MS spectrum of ion $[\mathrm{dCurc}-\mathrm{H}+\mathrm{Zn}]^{+}$and for comparison the MS/MS spectrum of ion $[\mathrm{Curc}-\mathrm{H}+\mathrm{Zn}]^{+}$(it is worth noting that $\mathrm{Zn}$-curcumin complexes may have interesting pharmacological activities [30]).

Zinc complexes have shown the simplest mass spectrometric fragmentation pathway. The only abundant fragment ion formed from ion [Curc- $\mathrm{H}+\mathrm{Zn}]^{+}$is at $\mathrm{m} / z$ 177. It should be noted that the formation of ion at $m / z 177$ is not followed by the loss of $\mathrm{H}_{2} \mathrm{CO}$ molecules (ion at $\mathrm{m} / \mathrm{z}$ 147 was not formed from ion [Curc- $\mathrm{H}+\mathrm{Zn}]^{+}$). The only abundant fragment ions formed from ion $[\mathrm{dCurc}-\mathrm{H}+\mathrm{Zn}]^{+}$ 


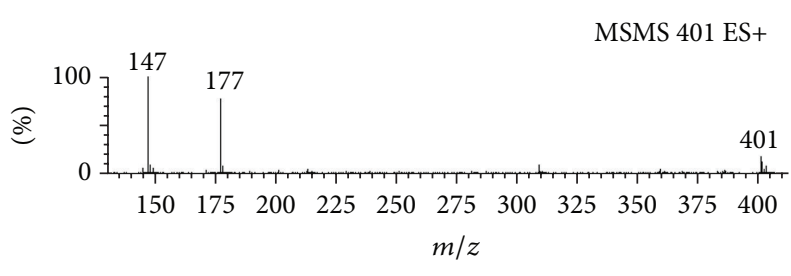

(a)

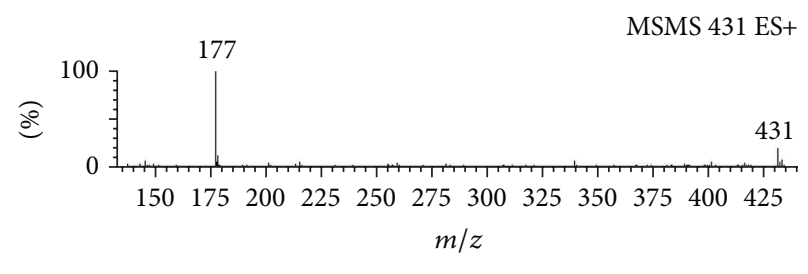

(b)

Figure 4: CID-MS/MS spectra of ion $[\mathrm{dCurc}-\mathrm{H}+\mathrm{Zn}]^{+}((\mathrm{a}) \mathrm{CE}=15 \mathrm{~V})$ and $[\mathrm{Curc}-\mathrm{H}+\mathrm{Zn}]^{+}((\mathrm{b}) \mathrm{CE}=15 \mathrm{~V})$.

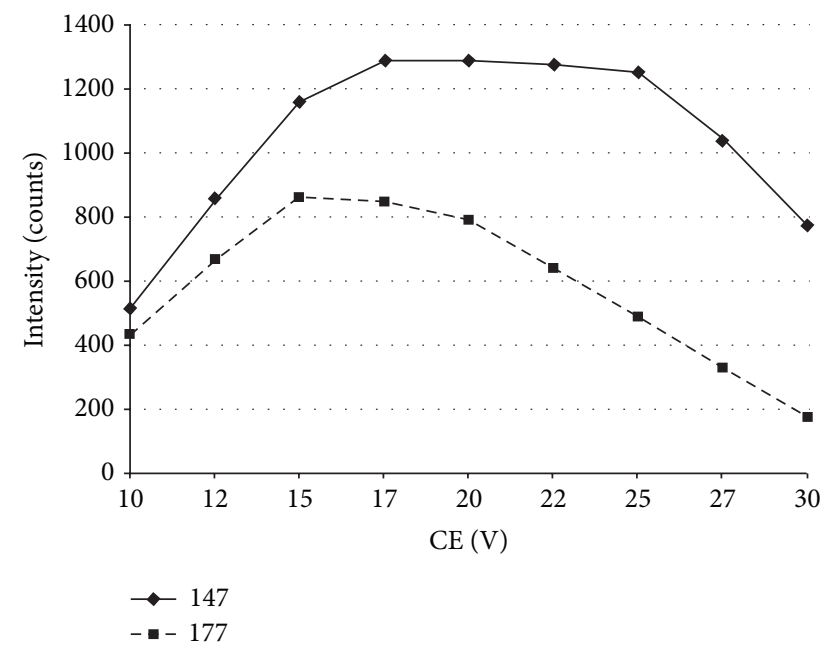

FIGURE 5: Plot of abundances of ions at $m / z 147$ and $m / z 177$ versus CE.

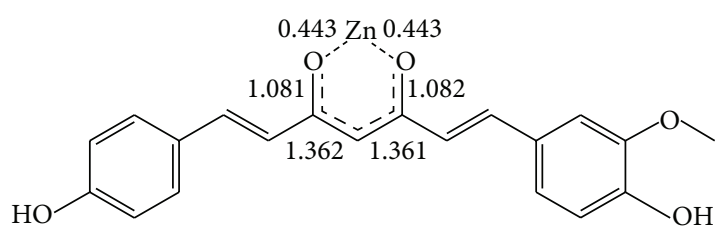

Figure 6: Bond orders of $[\mathrm{dCurc}-\mathrm{H}+\mathrm{Zn}]^{+}$ion.

are at $m / z 177$ and 147 (analogously as for ion [dCurc + $\mathrm{H}^{+}$). Figure 5 shows the plot of the abundance of ions at $\mathrm{m} / z$ 177 and 147 (originated from ion [dCurc-H $+\mathrm{Zn}]^{+}$) versus collision energies. As presented in Figure 5, the formation of ion at $m / z 147$ is always favoured over the formation of ion at $m / z 177$, independently of collision energy. This finding confirms that structure B1 predominates over structure B2. In this case, quantum mechanics calculations indicate that the $\mathrm{Zn}$ atom interacts with both halves of demethoxycurcumin molecule in the $[\mathrm{dCurc}-\mathrm{H}+\mathrm{Zn}]^{+}$ion almost equally strongly (Figure 6), as the bond orders of CC bonds are practically the same- 1.362 and 1.361 . Thus, the observed high abundance of ion at $m / z 147$ over the ion at $m / z 177$ does not result from the structure of ion $[\mathrm{dCurc}-\mathrm{H}+\mathrm{Zn}]^{+}$in the ground state. The only plausible explanation is that under CID conditions, the bond orders (energies) have to change in such a way that formation of ion at $m / z 147$ is favoured over the ion at $m / z 177$. In other words, for demethoxycurcumin-metal complexes structure, B1 predominates over structure B2 in the excited state.

The complexes of dCurc with other metal ions had more complicated mass spectrometric decomposition than zinc complexes. Figure 7 shows the MS/MS spectra of ions $[\mathrm{dCurc}-\mathrm{H}+\mathrm{Co}]^{+}$and $[\mathrm{dCurc}-\mathrm{H}+\mathrm{FeCl}]^{+}$and for comparison the MS/MS spectra of ions $[\mathrm{Curc}-\mathrm{H}+\mathrm{Co}]^{+}$and $[\mathrm{Curc}-\mathrm{H}+$ $\mathrm{FeCl}]^{+}$. Differences of intensities between $m / z 147$ and 177 are clearly visible.

Mass spectrometric decomposition of these ions yielded a number of fragment ions. Detailed interpretation of the CIDMS/MS spectra obtained is not the aim of the study. What matters is the presence of relatively abundant ions at $\mathrm{m} / z$ 147 and a lower abundance of ion at $m / z 177$ formed from ions $[\mathrm{dCurc}-\mathrm{H}+\mathrm{Co}]^{+}$and $[\mathrm{dCurc}-\mathrm{H}+\mathrm{FeCl}]^{+}$. Therefore, structure B1 seems predominant over structure B2 for both cobalt and iron complexes.

\section{Conclusion}

The ESI-MS/MS spectra obtained of the ions containing demethoxycurcumin, curcumin, and metal cation have indicated that, for some metals, curcumin-metal complexes are more stable than demethoxycurcumin-metal complexes and for some metals vice versa. That is, lack/presence of methoxyl moiety at aromatic ring essentially affects the stability of curcuminoid-metal complexes. In the presented examples curcumin was more prone to bind divalent metal cations, and demethoxycurcumin was more prone to bind trivalent metal cations. In one of the studied cases, namely in Cd-complexes, both curcumin and demethoxycurcumin appeared to form complexes of the same stabilities.

In three of presented examples of demethoxycurcuminmetal complexes, structure B1 predominated over tautomer structure B2 since ions at $\mathrm{m} / z 147$ were more abundant than those at $m / z$ 177. However, this is not the feature of demethoxycurcumin molecule since for ion $[\mathrm{dCurc}+\mathrm{H}]^{+}$ion at $m / z 177$ was more abundant than that at $m / z 147$ [51].

\section{Conflict of Interests}

Authors of the paper do not have a direct financial relation with the commercial identities (Sigma-Aldrich, Waters/Micromass) mentioned in this paper. 


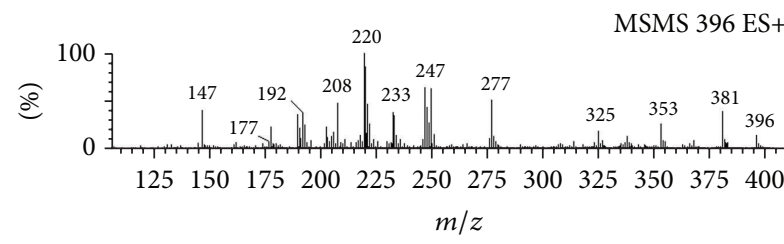

(a)

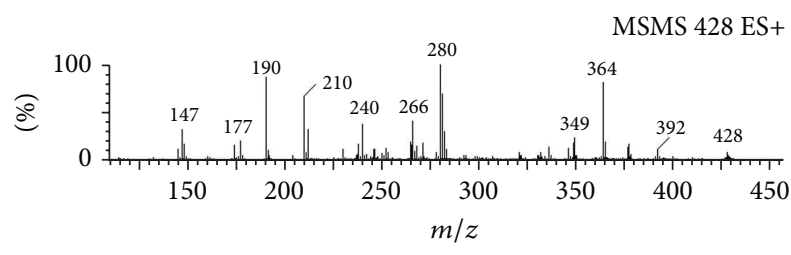

(c)

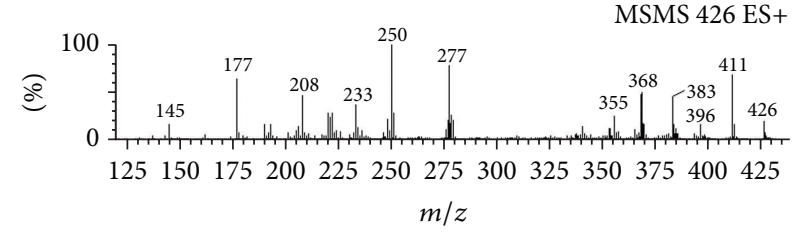

(b)

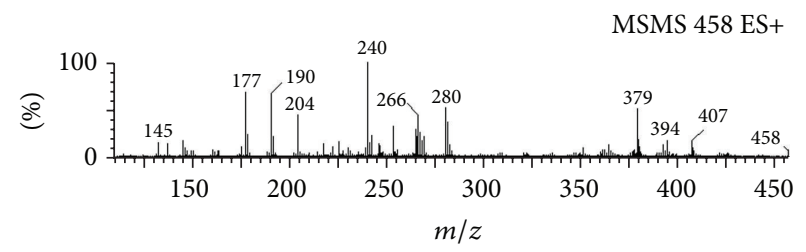

(d)

Figure 7: CID-MS/MS spectra of ions $[\mathrm{dCurc}-\mathrm{H}+\mathrm{Co}]^{+}((\mathrm{a}) \mathrm{CE}=20 \mathrm{~V})$ and $[\mathrm{dCurc}-\mathrm{H}+\mathrm{FeCl}]^{+}((\mathrm{c}) \mathrm{CE}=15 \mathrm{~V})$ and for comparison the $\mathrm{MS} / \mathrm{MS}$ spectra of ions $[\mathrm{Curc}-\mathrm{H}+\mathrm{Co}]^{+}((\mathrm{b}) \mathrm{CE}=20 \mathrm{~V})$ and $[\mathrm{Curc}-\mathrm{H}+\mathrm{FeCl}]^{+}((\mathrm{d}) \mathrm{CE}=20 \mathrm{~V})$.

\section{Acknowledgment}

This research was supported in part by PL-Grid Infrastructure.

\section{References}

[1] S. C. Gupta, S. Prasad, J. H. Kim et al., "Multitargeting by curcumin as revealed by molecular interaction studies," Natural Product Reports, vol. 28, no. 12, pp. 1937-1955, 2011.

[2] S. Padhye, D. Chavan, S. Pandey, J. Deshpande, K. V. Swamy, and F. H. Sarkar, "Perspectives on chemopreventive and therapeutic potential of curcumin analogs in medicinal chemistry," Mini Reviews in Medicinal Chemistry, vol. 10, no. 5, pp. 372-387, 2010.

[3] S. C. Gupta, S. Patchva, W. Koh, and B. B. Aggarwal, "Discovery of curcumin, a component of golden spice, and its miraculous biological activities," Clinical and Experimental Pharmacology and Physiology, vol. 39, no. 3, pp. 283-299, 2012.

[4] H. Hatcher, R. Planalp, J. Cho, F. M. Torti, and S. V. Torti, "Curcumin: from ancient medicine to current clinical trials," Cellular and Molecular Life Sciences, vol. 65, no. 11, pp. 1631-1652, 2008.

[5] Y. L. Guo, X. Z. Li, and C. T. Kuang, "Antioxidant pathways and chemical mechanism of curcumin," Advanced Materials Research, vol. 236-238, pp. 2311-2314, 2011.

[6] A. Dairam, J. L. Limson, G. M. Watkins, E. Antunes, and S. Daya, "Curcuminoids, curcumin, and demethoxycurcumin reduce lead-induced memory deficits in male wistar rats," Journal of Agricultural and Food Chemistry, vol. 55, no. 3, pp. 1039-1044, 2007.

[7] S. Rege, S. Momin, S. Wadekar, A. Pratap, and D. Bhowmick, "Effect of demethoxycurcumin and bisdemethoxycurcumin on antioxidant activity of Curcumin in refined sunflower oil," Journal of Food Processing and Preservation, 2012.

[8] J. H. Kim, J. S. Shim, S.-K. Lee et al., "Microarray-based analysis of anti-angiogenic activity of demethoxycurcumin on human umbilical vein endothelial cells: crucial involvement of the down-regulation of matrix metalloproteinase," Japanese Journal of Cancer Research, vol. 93, no. 12, pp. 1378-1385, 2002.
[9] L. Y. Guo, X. F. Cai, J. J. Lee et al., "Comparison of suppressive effects of demethoxycurcumin and bisdemethoxycurcumin on expressions of inflammatory mediators in vitro and in vivo," Archives of Pharmacal Research, vol. 31, no. 4, pp. 490-496, 2008.

[10] H. Ahsan, N. Parveen, N. U. Khan, and S. M. Hadi, "Prooxidant, anti-oxidant and cleavage activities on DNA of curcumin and its derivatives demethoxycurcumin and bisdemethoxycurcumin," Chemico-Biological Interactions, vol. 121, no. 2, pp. 161-175, 1999.

[11] S. K. Sandur, M. K. Pandey, B. Sung et al., "Curcumin, demethoxycurcumin, bisdemethoxycurcumin, tetrahydrocurcumin and turmerones differentially regulate anti-inflammatory and anti-proliferative responses through a ROSindependent mechanism," Carcinogenesis, vol. 28, no. 8, pp. 1765-1773, 2007

[12] M.-T. Huang, N. Ma, Y.-P. Lu et al., "Effects of curcumin, demethoxycurcumin, bisdemethoxycurcumin and tetrahydrocurcumin on 12-O-tetradecanoylphorbol-13-acetate-induced tumor promotion," Carcinogenesis, vol.16, no. 10, pp. 2493-2497, 1995.

[13] D. K. Agrawal, D. Saikia, R. Tiwari et al., "Demethoxycurcumin and its semisynthetic analogues as antitubercular agents," Planta Medica, vol. 74, no. 15, pp. 1828-1831, 2008.

[14] C. M. Hung, Y. H. Su, H. Y. Lin et al., "Demethoxycurcumin modulates prostate cancer cell proliferation via AMPK-induced down-regulation of HSP70 and EGFR," Journal of Agricultural and Food Chemistry, vol. 60, pp. 8427-8434, 2012.

[15] S. Yodkeeree, W. Chaiwangyen, S. Garbisa, and P. Limtrakul, "Curcumin, demethoxycurcumin and bisdemethoxycurcumin differentially inhibit cancer cell invasion through the downregulation of MMPs and uPA," Journal of Nutritional Biochemistry, vol. 20, no. 2, pp. 87-95, 2009.

[16] F. Kühlwein, K. Polborn, and W. Beck, "Metal complexes of dyes. IX. Transition metal complexes of curcumin and derivatives," Zeitschrift fur Anorganische und Allgemeine Chemie, vol. 623, no. 8, pp. 1211-1219, 1997.

[17] B. Zebib, Z. Mouloungui, and V. Noirot, "Stabilization of curcumin by complexation with divalent cations in glycerol/water system," Bioinorganic Chemistry and Applications, vol. 2010, Article ID 292760, 8 pages, 2010. 
[18] M. H. M. Leung, D.-T. Pham, S. F. Lincoln, and T. W. Kee, "Femtosecond transient absorption spectroscopy of Copper(II)Curcumin complexes," Physical Chemistry Chemical Physics, vol. 14, pp. 13580-13587, 2012.

[19] X.-Z. Zhao, T. Jiang, L. Wang, H. Yang, S. Zhang, and P. Zhou, "Interaction of curcumin with $\mathrm{Zn}$ (II) and $\mathrm{Cu}$ (II) ions based on experiment and theoretical calculation," Journal of Molecular Structure, vol. 984, no. 1-3, pp. 316-325, 2010.

[20] J. Rajesh, M. Rajasekaran, G. Rajagopal, and P. Athappan, “Analytical methods to determine the comparative DNA binding studies of Curcumin-Cu(II) complexes," Spectrochimica Acta A, vol. 97, pp. 223-230, 2012.

[21] L. Shen, H.-Y. Zhang, and H.-F. Ji, "A theoretical study on $\mathrm{Cu}(\mathrm{II})$-chelating properties of curcumin and its implications for curcumin as a multipotent agent to combat Alzheimer's disease," Journal of Molecular Structure, vol. 757, no. 1-3, pp. 199202, 2005.

[22] T. Jiang, L. Wang, S. Zhang et al., "Interaction of curcumin with $\mathrm{Al}(\mathrm{III})$ and its complex structures based on experiments and theoretical calculations," Journal of Molecular Structure, vol. 1004, no. 1-3, pp. 163-173, 2011.

[23] S.-H. Kim, S.-Y. Gwon, S. M. Burkinshaw, and Y.-A. Son, "The photo- and electrophysical properties of curcumin in aqueous solution," Spectrochimica Acta A, vol. 76, no. 3-4, pp. 384-387, 2010.

[24] Z. Chen, L. Zhu, T. Song, J. Chen, and Z. Guo, "A novel curcumin assay with the metal ion $\mathrm{Cu}$ (II) as a simple probe by resonance light scattering technique," Spectrochimica Acta A, vol. 72, no. 3, pp. 518-522, 2009.

[25] Y.-M. Song, J.-P. Xu, L. Ding, Q. Hou, J.-W. Liu, and Z.-L. Zhu, "Syntheses, characterization and biological activities of rare earth metal complexes with curcumin and 1,10-phenanthroline5,6-dione," Journal of Inorganic Biochemistry, vol. 103, no. 3, pp. 396-400, 2009.

[26] H.-C. Huang, C.-J. Lin, W.-J. Liu, R.-R. Jiang, and Z.-F. Jiang, "Dual effects of curcumin on neuronal oxidative stress in the presence of $\mathrm{Cu}(\mathrm{II})$, , Food and Chemical Toxicology, vol. 49, no. 7, pp. 1578-1583, 2011.

[27] L. Baum and A. Ng, "Curcumin interaction with copper and iron suggests one possible mechanism of action in Alzheimer's disease animal models," Journal of Alzheimer's Disease, vol. 6, no. 4, pp. 367-377, 2004.

[28] S. Daniel, J. L. Limson, A. Dairam, G. M. Watkins, and S. Daya, "Through metal binding, curcumin protects against lead- and cadmium-induced lipid peroxidation in rat brain homogenates and against lead-induced tissue damage in rat brain," Journal of Inorganic Biochemistry, vol. 98, no. 2, pp. 266-275, 2004.

[29] H. Oguzturk, O. Ciftci, M. Aydin, N. Timurkaan, A. Beytur, and F. Yilmaz, "Ameliorative effects of Curcumin against acute cadmium toxicity on male reproductive system in rats," Andrologia, vol. 44, pp. 243-249, 2012.

[30] X. Mei, D. Xu, S. Xu, Y. Zheng, and S. Xu, "Gastroprotective and antidepressant effects of a new zinc(II)-curcumin complex in rodent models of gastric ulcer and depression induced by stresses," Pharmacology Biochemistry and Behavior, vol. 99, no. 1, pp. 66-74, 2011.

[31] R. Agarwal, S. K. Goel, and J. R. Behari, "Detoxification and antioxidant effects of curcumin in rats experimentally exposed to mercury," Journal of Applied Toxicology, vol. 30, no. 5, pp. 457468,2010 .
[32] A. Valentini, F. Conforti, A. Crispini et al., "Synthesis, oxidant properties, and antitumoral effects of a heteroleptic palladium(II) complex of curcumin on human prostate cancer cells," Journal of Medicinal Chemistry, vol. 52, no. 2, pp. 484-491, 2009.

[33] P. Singh, P. Mogra, V. Sankhla, and K. Deora, "Protective effects of curcumin on cadmium chloride induced colon toxicity in Swiss albino mice," Journal of Cell and Molecular Biology, vol. 9, no. 1, pp. 31-36, 2011.

[34] R. J. Shiau, J. Y. Wu, S. J. Chiou, and Y. D. Wen, "Effects of Curcumin on nitrosyl-iron complex-mediated DNA cleavage and cytotoxicity," Planta Medica, vol. 78, pp. 1342-1350, 2012.

[35] G. Modi and K. S. Pitre, "The role of Fe(II) in the increased medicinal potency of curcumin analyzed by electrochemical methods," Journal of Coordination Chemistry, vol. 62, no. 6, pp. 931-939, 2009.

[36] R. H. Hertwig and W. Koch, "On the parameterization of the local correlation functional. What is Becke-3-LYP?" Chemical Physics Letters, vol. 268, no. 5-6, pp. 345-351, 1997.

[37] M. Dolg, U. Wedig, H. Stoll, and H. Preuss, "Energy-adjusted ab initio pseudopotentials for the first row transition elements," The Journal of Chemical Physics, vol. 86, no. 2, pp. 866-872, 1987.

[38] K. B. Wiberg, "Application of the pople-santry-segal CNDO method to the cyclopropylcarbinyl and cyclobutyl cation and to bicyclobutane," Tetrahedron, vol. 24, no. 3, pp. 1083-1096, 1968.

[39] A. E. Reed, R. B. Weinstock, and F. Weinhold, "Natural population analysis," The Journal of Chemical Physics, vol. 83, no. 2, pp. 735-746, 1985.

[40] M. J. Frisch, G. W. Trucks, H. B. Schlegel et al., Wallingford CT, 2009.

[41] R. G. Cooks, J. S. Patrick, T. Kotiaho, and S. A. McLuckey, "Thermochemical determinations by the kinetic method," Mass Spectrometry Reviews, vol. 13, no. 4, pp. 287-339, 1994.

[42] R. G. Cooks and P. S. H. Wong, "Kinetic method of making thermochemical determinations: advances and applications," Accounts of Chemical Research, vol. 31, no. 7, pp. 379-386, 1998.

[43] L. Wu, W. A. Tao, and R. G. Cooks, "Ligand and metalion effects in metal-ion clusters used for chiral analysis of $\alpha$ hydroxy acids by the kinetic method," Analytical and Bioanalytical Chemistry, vol. 373, no. 7, pp. 618-627, 2002.

[44] L. Wu, K. Lemr, T. Aggerholm, and R. G. Cooks, "Recognition and quantification of binary and ternary mixtures of isomeric peptides by the kinetic method: Metal ion and ligand effects on the dissociation of metal-bound complexes," Journal of the American Society for Mass Spectrometry, vol. 14, no. 2, pp. 152160, 2003.

[45] R. Frański and B. Gierczyk, "Formation of organometallic species, $[\mathrm{M}-\mathrm{H}]^{+}$ions and radical cations upon mass spectrometric fragmentation of mercury-crown ether complexes," European Journal of Mass Spectrometry, vol. 15, no. 4, pp. 479486, 2009.

[46] P. E. Allegretti, M. de las Mercedes Schiavoni, E. A. Castro, and J. J. P. Furlong, "Tautomeric equilibria studies by mass spectrometry," World Journal of Chemistry, vol. 2, pp. 25-62, 2007.

[47] P. B. Terent'ev and A. G. Kalandarishvili, "Application of mass spectrometry for the analysis of organic tautomeric compounds," Mass Spectrometry Reviews, vol. 15, no. 6, pp. 339-363, 1996.

[48] J. J. P. Furlong, M. M. Schiavoni, E. A. Castro, and P. E. Allegretti, "Mass spectrometry as a tool for studying tautomerism," Russian Journal of Organic Chemistry, vol. 44, no. 12, pp. 17251736,2008 
[49] B. Avula, Y. H. Wang, and I. A. Khan, "Quantitative determination of curcuminoids from the roots of Curcuma longa, Curcuma species and dietary supplements using an UPLC-UVMS method," Journal of Chromatography, vol. 3, no. 1, pp. 1-6, 2012.

[50] K. Inoue, C. Nomura, S. Ito, A. Nagatsu, T. Hino, and H. Oka, "Purification of curcumin, demethoxycurcumin, and bisdemethoxycurcumin by high-speed countercurrent chromatography," Journal of Agricultural and Food Chemistry, vol. 56, no. 20, pp. 9328-9336, 2008.

[51] R. V. Coorey and P. Hakansson, "Applicaiton of mass spectrometry to characterize the components present in a Curcumin sample," Sri Lankan Journal of Physics, vol. 4, pp. 11-20, 2003. 

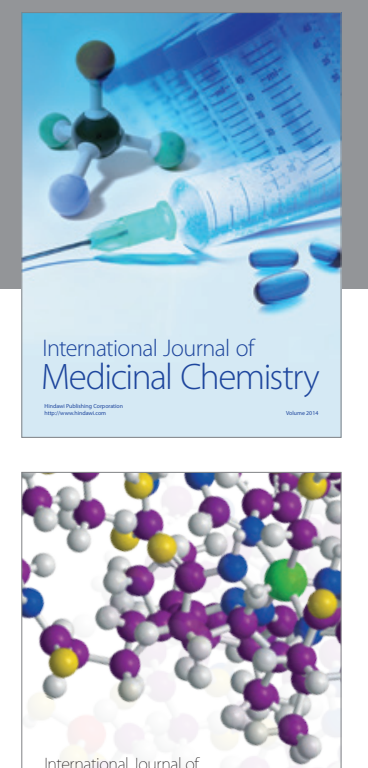

\section{Carbohydrate} Chemistry

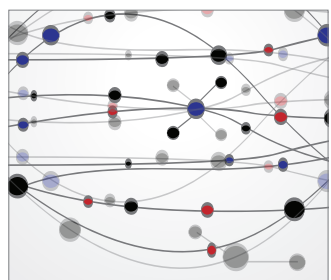

The Scientific World Journal
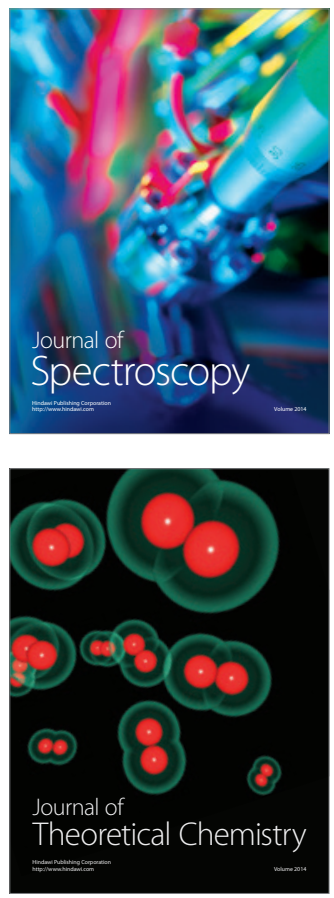
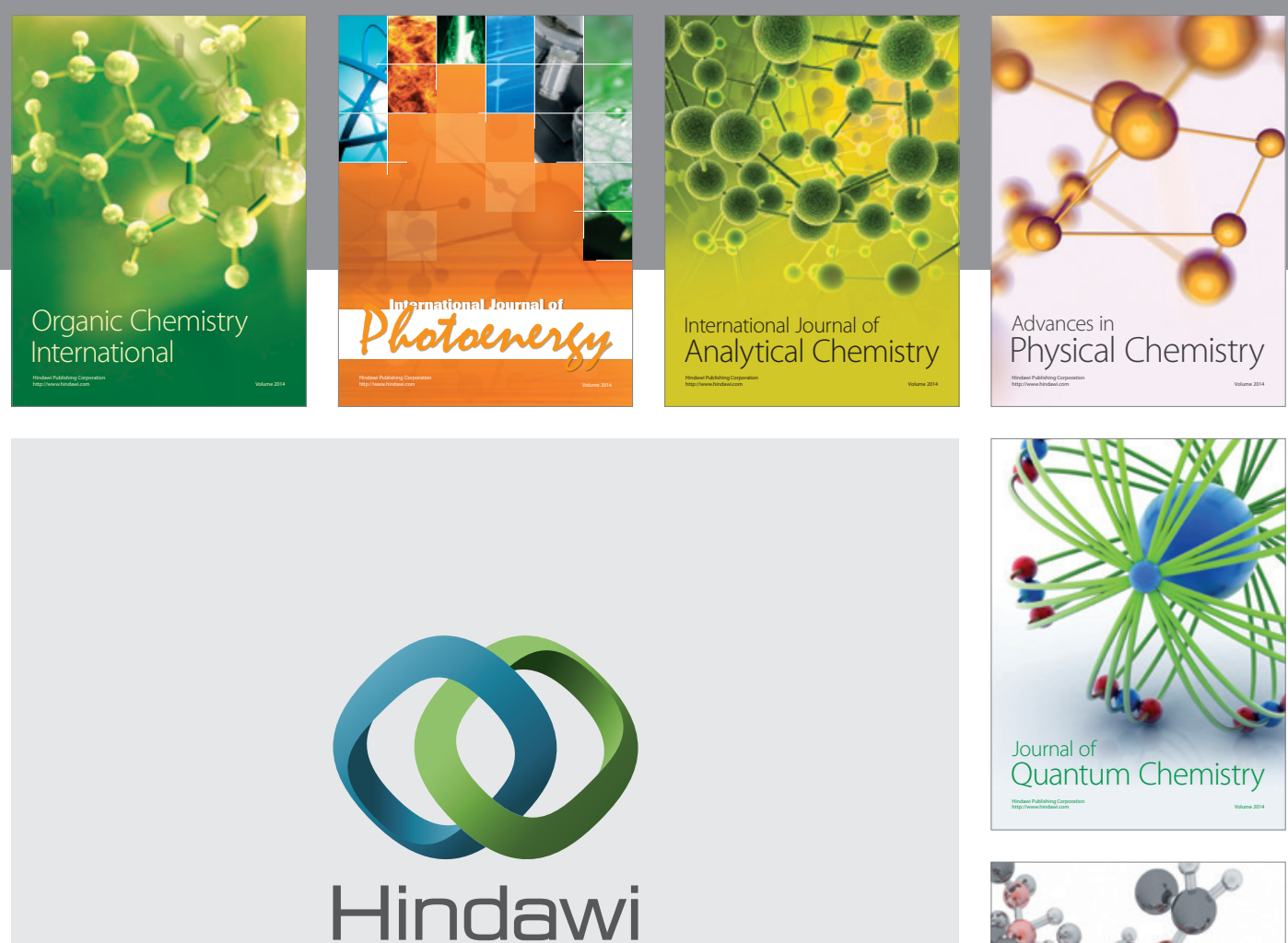

Submit your manuscripts at

http://www.hindawi.com

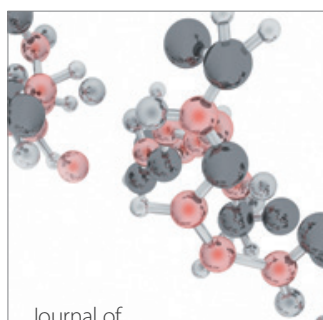

Analytical Methods

in Chemistry

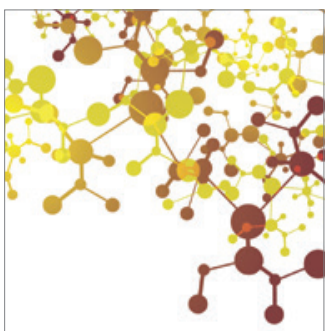

Journal of

Applied Chemistry

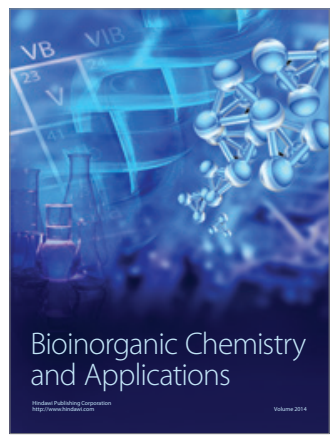

Inorganic Chemistry
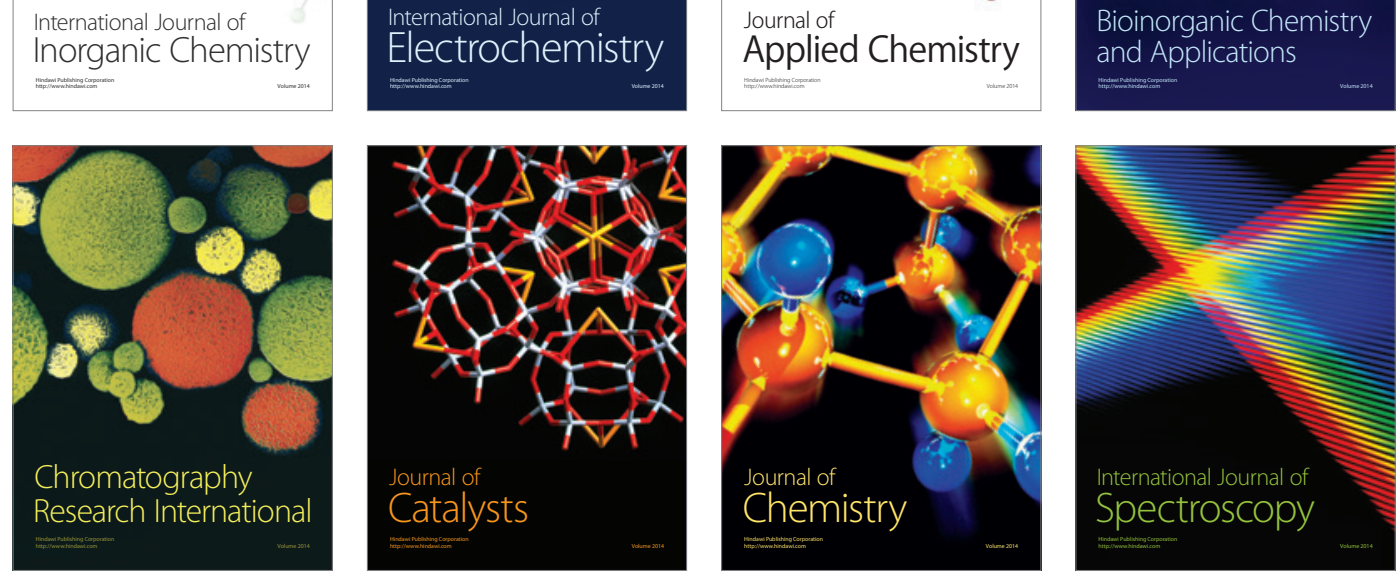